\title{
Identification of the Cerebral Neurosecretory Cells That Contain Eclosion Hormone in the Moth Manduca sexta
}

\author{
Philip F. Copenhaver ${ }^{-1}$ and James W. Truman \\ Department of Zoology NJ-15, University of Washington, Seattle, Washington 98195
}

Eclosion hormone (EH) is an insect neuropeptide that is released at the end of metamorphosis from the CNS and triggers the stereotyped motor program of adult emergence. Using three distinct experimental approaches, we have identified a discrete set of neurosecretory cells in the brain of the moth Manduca sexta that contains and releases EH. By isolating the neurosecretory somata and testing them with a sensitive behavioral bioassay, we identified a cluster of ipsilaterally projecting cells (Group Ia) that contain EH. Intracellular stimulation of individual cells within this group induced the release of bioactive EH into the hemolymph surrounding the neurohemal organs of the brain, whereas stimulation of cells in the other cerebral neurosecretory clusters did not. We also developed a polyclonal antiserum against purified EH that precipitated all bioactive material from samples containing the peptide. This antiserum selectively stained 5 of the Group Ia cells on either side of the brain, as well as their central and terminal processes. Preincubation of the serum with EH dramatically reduced its ability to bind the peptide subsequently. The combined application of these physiological and immunological techniques has led to the unequivocal identification of the EH neurons in the moth brain.

The neuroendocrine systems of insects contribute to the regulation of a wide variety of developmental and behavioral processes, coordinating an animal's responses to both internally and externally derived stimuli. The relative simplicity of the arthropod CNS has made possible the unambiguous identification of peptidergic cells and cell groups (Bullock, 1984; Rowell, 1976), and direct analysis of the contents of individual neurosecretory somata has revealed the cellular localization of peptides that modulate steroid secretion (Agui et al., 1979), diuresis (Berlind and Maddrell, 1979), skeletal muscle contraction (O'Shea and Bishop, 1982), heartbeat acceleration (O'Shea and Adams, 1981; Tublitz and Truman, 1985), and stage-specific cuticular tanning (Taghert and Truman, 1982). The electrophysiological properties of individual neurosecretory cells have also been determined in several different preparations (Bruce and Wilkens, 1976; Carrow et al., 1984; Miyazaki, 1980; Zaretsky and Loher, 1983), although attempts to monitor the spontaneous activity of peptidergic neurons in a physiologically relevant context have proven less successful.

We have been investigating the regulation of eclosion hormone (EH) in the moth Manduca sexta, a 4000 Da peptide secreted into the hemolymph from the CNS at the end of adult

\footnotetext{
Received Sept. 6, 1985; revised Nov. 7, 1985; accepted Nov. 14, 1985.

We wish to thank Drs. L. M. Riddiford and J. S. Edwards for their helpful comments on this manuscript, and Dr. J. C. Weeks for valuable instruction in intracellular recording techniques. This research was supported by an NIH Predoctoral Traineeship to P.F.C. (NSRA 2 T32 GM07270), NIH Grant NS13079, and NSF Grant DCB-8316055.

Correspondence should be addressed to Dr. Copenhaver.

I Present address: Department of Anatomy and Neurobiology, Washington University School of Medicine, Box 8108, 660 S. Euclid Ave., St. Louis, MO 63110. Copyright (c) 1986 Society for Neuroscience $0270-6474 / 86 / 061738-10 \$ 02.00 / 0$
}

development that triggers the stereotyped motor pattern of adult emergence (eclosion) from the pupal cuticle (Truman, 1971). Previous studies have indicated that EH is produced by cells in the brain and is transported to the associated neurohemal organs, the corpora cardiaca-allata complex (CC-CA), for storage and release (Truman, 1980). This system is of particular interest because the release of $\mathrm{EH}$ is tightly regulated by two factors: The declining titer of the steroid 20-hydroxyecdysone during the latter part of metamorphosis determines the day of $\mathrm{EH}$ secretion (Truman et al., 1983), while a circadian input determines the time of day when release occurs (Truman, 1972). These regulatory events can be experimentally manipulated in both intact and semi-intact animals (Schwartz and Truman, 1984; Truman et al., 1983), and the spontaneous activity of the cerebral neurosecretory system can be monitored electrophysiologically during the time of hormonal release (Copenhaver and Truman, 1984, 1986b).

In this report we have identified the EH-producing neurons of the moth brain by three separate experimental approaches. We have developed techniques for the dissection and bioassay of the various neurosecretory cell groups known to project to the CC-CA, thereby localizing EH to a bilaterally paired cluster in the lateral protocerebrum. We have confirmed these findings by electrical stimulation of individual cells within this group to induce the release of bioactive material and have prepared a polyclonal antiserum to EH that selectively stains 5 of the somata within each lateral cluster but does not stain any of the other neurons of the brain.

\section{Materials and Methods}

\section{Experimental animals}

Manduca sexta larvae were reared in a laboratory colony on an artificial diet (Bell and Joachim, 1976) and maintained in a long-day photoperiod of $17 \mathrm{hr}$ light: $7 \mathrm{hr}$ dark at $27^{\circ} \mathrm{C}$. Following pupation, animals were transferred to a photoperiod of $12 \mathrm{hr}$ light: $12 \mathrm{hr}$ dark with a superimposed thermoperiodic cycle $\left(27^{\circ} \mathrm{C}\right.$ by day : $25^{\circ} \mathrm{C}$ by night) to improve the synchrony of eclosion. Under these conditions, adult development is completed in approximately $18 \mathrm{~d}$. For the isolation of neurosecretory cell clusters or stimulation of individual somata, animals were selected on the day beforc cclosion (day 17 of adult development), using a defined set of cuticular markers (Schwartz and Truman, 1983). Animals that had completed adult development (day 18) were excluded from these studies to avoid potential interference from spontaneously released EH (Truman et al., 1983). Specimens to be used for immunohistochemical studies were injected with colchicine $(50 \mu \mathrm{l}$ of a $0.1 \%$ solution in physiological saline) on the 15th day of adult development and then killed $2 \mathrm{~d}$ later for collection of their neural tissue.

\section{Bioassay of $E H$}

The levels of $E H$ in cell homogenates and hemolymph samples were measured using a sensitive bioassay based on the stimulatory effect of the peptide on larval ecdysis (Truman et al., 1981). Staged Manduca larvae undergoing the molt to the fourth instar were maintained at $22.5^{\circ} \mathrm{C}$ and carefully monitored by reference to a defined set of external 
markers (Copenhaver and Truman, 1982). Animals were injected with 5-10 $\mu$ l of a sample solution using a $50 \mu \mathrm{l}$ microsyringe (Unimetrics) at a stage $4( \pm 0.5) \mathrm{hr}$ before the normal onset of ecdysis ( $1 \mathrm{hr}$ after the appearance of air in the exuvial headcap). Solutions containing EH caused a dose-dependent acceleration in the onset of the larval ecdysis behavior, and the amount of hormone present in a given sample could be estimated with respect to a standard curve (Fig. 1). Maximal responses were manifested by a premature initiation of the ecdysis behavior as early as $60 \mathrm{~min}$ after an injection, while latencies greater than $175 \mathrm{~min}$ were considered negative. The threshold of sensitivity for this assay is approximately $2 \times 10^{-4}$ units, one unit being defined as the amount of EH present in one CC-CA pair collected from a pharate adult moth (Reynolds and Truman, 1980).

\section{Isolation of neurosecretory cell somata}

Individual neurosecretory cells were isolated from the brains of developing adult moths by using a modification of the cell dispersal technique developed by $D$. Reddy (personal communication). Brains were dissected from $\mathrm{CO}_{2}$-anesthetized animals and the superficial tracheae and perineurial sheath carefully removed with fine forceps, while maintaining the tissuc under a physiological saline (Miyazaki, 1980) designed to mimic extracellular conditions within the CNS (in mM: $\mathrm{NaCl}, 140 ; \mathrm{KCl}$, 5; $\mathrm{CaCl}_{2}, 2.4 ; \mathrm{MgCl}_{2}, 1.3$; glucose, $10 ;$ HEPES buffered at $\mathrm{pH}$ 7.4). The desheathed brains were then incubated in a solution of $1 \mathrm{mg} / \mathrm{ml}$ collagenase (Type V; Sigma) and $1 \mathrm{mg} / \mathrm{ml}$ hyaluronidase (Type IV; Sigma) in saline for a period of $4-6 \mathrm{hr}$ at $22.5^{\circ} \mathrm{C}$ or overnight at $4^{\circ} \mathrm{C}$. Increased times of incubation resulted in more easily dissociated cells but also rendered the isolated somata more prone to spontaneous lysis.

Following this enzymatic treatment, brains were transferred to fresh saline and restrained with "minutien" insect pins. Under oblique lighting with a fiberoptics illuminator, the neurosecretory cell bodies were easily visualized due to their differential diffraction of light. The individual somata (and occasionally a portion of their axons) could then be teased gently from the surrounding tissue with finely pulled glass needles, frecd from any residual matcrial, and transferred to a 5-10 $\mu$ l droplet of saline under paraffin oil. The droplets were exposed to repeated freezethawing to induce cell lysis and subsequently were collected with a microsyringe. By this method, both individual and pooled subsets of neurosecretory cells could be maintained and manipulated in a controlled volume for bioassay of their contents.

\section{Intracellular stimulation of neurosecretory cells}

Electrical stimulation of individual neurosecretory cells was accomplished using a semi-intact preparation: Pharate adults were anesthetized with $\mathrm{CO}_{2}$, restrained in molded Plasticine by inserting insect pins through the thoracic wing bases and the anteriolateral regions of the headcap, and the cuticle above the brain and CC-CA was surgically removed. The heart and large tracheal trunks overlying the brain were then ligated with fine silk thread and a longitudinal incision made in the heart to expose completely the bilaterally paired CC-CA. Removal of the largest tracheal branches investing the dorsal surface of the brain facilitated the visualization of the neurosecretory cells in the protocerebrum. Care was taken not to disrupt the perineurial sheath, as damage to this structure resulted in extreme deformation of the cerebral lobes.

The brain was then stabilized with a waxed metal platform and individual neurosecretory somata were impaled with a glass micropipette electrode (30-60 m $)$ filled with $2 \mathrm{~m}$ potassium acetate. Intracellular recordings were performed using a Getting model 5 microelectrode amplifier and monitored on a multiple-trace storage oscilloscope. To induce the release of neurosecretory material from a cell's terminals in the CCCA, a stimulation paradigm of $100 \mathrm{msec}$ depolarizing pulses $(2-10 \mathrm{nA})$ at $1-2 \mathrm{~Hz}$ for $10 \mathrm{~min}$ was chosen to mimic the maximum firing frequencies recorded in the neurosecretory nerves during spontaneous bouts of activity (Copenhaver and Truman, 1984, 1986b). The amount of current injected was adjusted to maintain continuous firing by the cell. Samples of the bath surrounding the CC-CA were collected just before and after the period of stimulation and immediately bioassayed for the presence of $\mathrm{EH}$.

Under visual guidance, the stimulated cell could then be reimpaled reliably with an electrode containing $125 \mathrm{~mm}$ cobalt chloride, which was iontophoresed by passing $800 \mathrm{msec}$ depolarizing pulses of current $(20 \mathrm{nA})$ at $1 \mathrm{~Hz}$ for $10-15 \mathrm{~min}$. Subsequently, the preparation was incubated for 4-6 hr to allow diffusion of the cobalt throughout the cell's processes. The brain-CC-CA complex was then dissected, transferred to a solution of $0.5 \%$ ammonium sulfide in saline for $20 \mathrm{~min}$ to

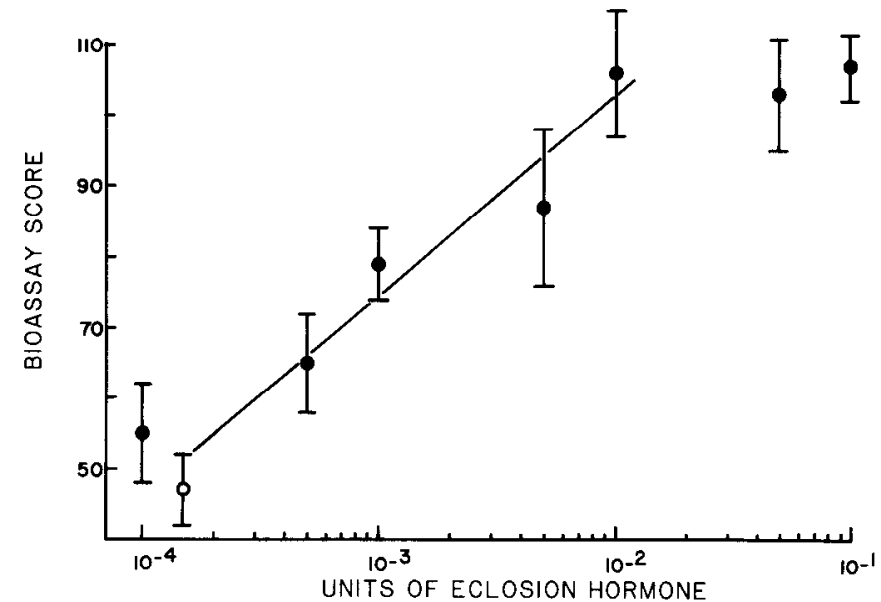

Figure 1. Bioassay for EH based on larval ecdysis. Serial dilutions of $\mathrm{EH}$ were injected into larvae at a stage $4 \pm 0.5 \mathrm{hr}$ before the normal onset of ecdysis to the fourth larval instar. (One unit of EH is defined as the amount of biological activity present in the CC-CA of a pharate adult moth.) The bioassay score was calculated as the inverse of the latency $(\mathrm{min})$ between the time of injection and onset of ecdysis behavior $\times 10^{4}$. Scores less than 57 (representing latencies greater than $175 \mathrm{~min}$ ) were considered negative. Open circle represents scores for uninjected controls and animals injected with saline. Each point represents at least 10 animals $( \pm \mathrm{SE})$.

precipitate the cobalt, rinsed, and placed in Carnoy's fixative for $1 \mathrm{hr}$. Silver intensification of the filled cells was performed according to the method of Bacon and Altman (1977), followed by mounting of the tissue in Canada balsam.

\section{Production of $E H$ antibodies}

For preparation of a serum antibody to $\mathrm{EH}$, the hormonal content of 1000 CC-CA pairs was extracted by high-pressure liquid chromatography (HPLC) (J. W. Truman and G. Terzi, unpublished observations). One CC-CA pair is estimated to contain 1-10 ng EH. The peptide was conjugated overnight to BSA (RIA grade; Sigma) in a molar ratio of 6:1, using the glutaraldehyde technique (Watson and Akil, 1983). The conjugation reaction was then inactivated by adding $2 \mathrm{mg}$ sodium borohydride/ml glutaraldehyde (Bulinski et al., 1983) and centrifuged at $50,000 \times \mathrm{g}$ for $30 \mathrm{~min}$. The resulting pellet was resuspended in $1 \mathrm{ml}$ of Sorenson's buffered saline and emulsified with $1 \mathrm{ml}$ Freund's complete adjuvant. In addition, $100 \mu \mathrm{g}$ muramyl dipeptide (Adjuvant Peptide; Sigma) was added to the mixture as an additional stimulant of the immune response (Chedid et al., 1976). The emulsified solution was then administered to a rabbit by multiple subcutaneous injections.

This procedure was repeated every 3-4 weeks for 8 months, utilizing an approximate total of 10,000 CC-CA. Serum samples were periodically collected from an ear vein using a $35 \mathrm{ml}$ syringe (offset tip; Monoject) and a 21 gauge Luer-Lok needle. By this method a substantial volume of blood could be collected without causing excessive hemolysis of the sample or trauma to the car vcin. Blood was allowed to clot at $27^{\circ} \mathrm{C}$ for $6-8 \mathrm{hr}$ and centrifuged at $50,000 \times \mathrm{g}$ for $30 \mathrm{~min}$ at $10^{\circ} \mathrm{C}$. The resultant serum was aliquoted and stored with $0.1 \%$ sodium azide at $-70^{\circ} \mathrm{C}$.

The presence of specific antibody binding activity was monitored by the immunoprecipitation procedure of Jones (1980). Briefly, aqueous extracts of $\mathrm{EH}$ (at a concentration of $1 \mathrm{unit} / 30 \mu \mathrm{l}$ ) were prepared from pharate adult CC-CA by homogenization of the glands in saline and heat treatment of $80^{\circ} \mathrm{C}$ for $5 \mathrm{~min}$. The extracts were then centrifuged to remove particulate matter, and the supernatant was divided into 100 $\mu \mathrm{l}$ aliquots. Each aliquot was incubated with $50 \mu \mathrm{l}$ of a serum sample (diluted from 1:5 to 1:500) for $30 \mathrm{~min}$, followed by $50 \mu \mathrm{l}$ of an aqueous solution of Protein A (IgGsorb; the Enzyme Center, Inc.) for an additional $30 \mathrm{~min}$. All incubations were performed on ice with intermittent agitation. The immunoglobulin-Protein A complex was pelleted by a 2 min centrifugation in a microfuge (Beckman) and the supernatant bioassayed for the presence of residual EH. A strong affinity of the serum for the peptide resulted in a negative bioassay score, indicating that all bioactive material had been successfully precipitated. Extracts contain- 


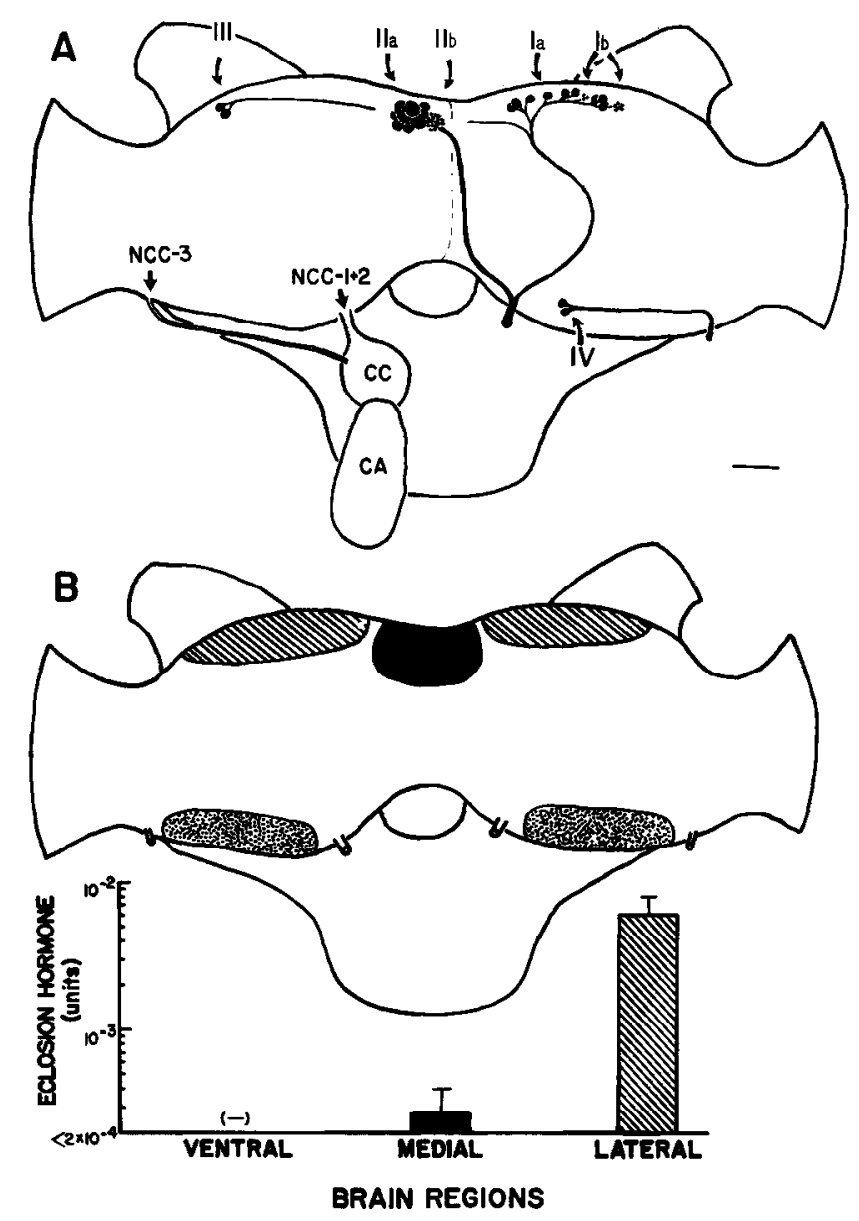

Figure 2. A, Schematic representation of the cell groups in the brain that project to the CC-CA in adult Manduca. Only one set of each bilaterally paired cluster is shown. Protocerebral Groups Ia and Ib project to the ipsilateral CC-CA via nerve NCC-1+2, while Groups IIa, IIb, and III send their axons across the midline to the contralateral nerve. The tritocerebral Group IV cells project to the ipsilateral CCCA via nerve NCC-3. $B$, Bioassay of the various regions of the adult moth brain that contain the neurosecretory cell groups. ( $n \geq 10$ for each histogram.)

ing EH were routinely pretreated with an aliquot of Protein A (20 $\mu \mathrm{l} /$ $100 \mu \mathrm{l}$ of extract) prior to the immunoprecipitation procedure to control for nonspecific binding of the hormone. Other controls included the incubation of aliquots of the EH extract with preimmune serum or with saline.

Serum samples were also preblocked with extracts from a variety of neural and non-neural tissues to determine their ability to interfere with the immunoprecipitation reaction. The protocerebral lobes, optic lobes, or CC-CA complexes of 10 pharate adult brains were homogenized in $500 \mu \mathrm{l}$ of saline, and $100 \mu \mathrm{l}$ of each of these extracts was added to an equal volume of the immune serum for overnight incubation at $4^{\circ} \mathrm{C}$. Extracts prepared from larval muscle and fat body $(1.5 \mathrm{gm}$ in $2 \mathrm{ml}$ saline) were similarly employed. The preblocked serum samples were subsequently tested by immunoprecipitation as already described.

\section{Immunohistochemistry}

Immunohistochemical staining of nervous tissue from pharate adult moths was performed using the indirect immunofluorescent technique (Sternberger, 1979). Brains were dissected from colchicine-pretreated animals (as previously described) and stored in Bouin's fixative (aqueous) for 12-24 hr. The tissue was then rinsed, dehydrated, and embedded in paraffin (Surgipath). Serial sections, $8 \mu \mathrm{m}$, were cut on a rotary microtome and affixed to gelatin-coated slides. Processing of the tissue was performed by standard immunohistochemical procedures: The sections were deparaffinized, rehydrated, and blocked for $1 \mathrm{hr}$ in $20 \mathrm{~mm}$ PBS containing $1 \%$ BSA, 3\% normal goat serum, and $0.1 \%$ sodium azide (PBS-BNA). The anti-EH serum was preabsorbed with $1 \%$ BSA in PBS for 12-24 hr, diluted with PBS-BNA, and applied to the tissue scctions for incubation (for $36-48 \mathrm{hr}$ at $4^{\circ} \mathrm{C}$ ). Concentrations from $1: 10$ to $1: 1000$ were tested for their ability to stain the nervous system, but a dilution of 1:100 was most commonly employed. Subsequently, the sections were rinsed in PBS, incubated with a secondary antibody conjugated to fluorescein isothiocyanate (goat anti-rabbit IgG, 1:200 in PBSBNA) for 1-2 hr, and rinsed again. For mounting, $80 \%$ glycerol in PBS containing $4 \% N$-propyl gallate was used to retard photobleaching of the fluorescein (Giloh and Sedat, 1982). The specificity of the immunohistochemical reaction was tested by exposing serial adjacent sections either to immune or preimmune serum or to immune serum that had been preincubated with HPLC-purified EH for $24 \mathrm{hr}$ (500 units of EH in $100 \mu$ l of serum).

\section{Results}

\section{Localization of EH cells}

The cerebral neurosecretory system of adult $\mathrm{Manduca}$ includes 4 bilaterally paired groups of putative neurosecretory cells within the brain that send their axons to the CC-CA-Fig. $2 A$ (Copenhaver and Truman, 1986a). On either side of the brain there is a cluster of 2 cells (Group IV, $15 \mu \mathrm{m}$ ) in the ventral tritocerebrum and 3 distinct clusters in the dorsal protocerebrum: an ipsilateral group of 8-9 large cells (Group Ia, 15-20 $\mu \mathrm{m}$ ) projecting to the CC-CA via the adjacent nervi corporis cardiaci$I+2(\mathrm{NCC}-1+2)$; a contralateral pair of cells (Group III, 20 $\mu \mathrm{m})$ in the most lateral portion of the protocerebrum that send their axons out the NCC $-1+2$ on the opposite side of the brain; and a cluster of 9 large medial cells (Group IIa, 20-35 $\mu \mathrm{m}$ ) designated the contramedial cluster, as their axons also project across the midline before exiting the brain. Similar sets of cells have been identified in the larval and pupal stages of Manduca (Buys and Gibbs, 1981; Carrow et al., 1984; Nijhout, 1975).

Associated with these clusters of large cells in the adult are 2 groups of smaller neurons $(5-10 \mu \mathrm{m})$ that send processes to the NCC-1 +2 . The diffuse Group Ib, interspersed with the larger neurosecretory cells of the lateral protocerebrum (Nijhout, 1975), are not visible in the living tissue and were not investigated in this study. Group IIb, comprised of a tight packet of opalescent cells on either side of the dorsal midline (Copenhaver and Truman, 1986a), were routinely collected with the larger IIa cells (discussed below) but were not examined electrophysiologically.

When the lateral, medial, and ventral portions of the pharate adult brain containing the various neurosecretory cell groups were dissected and assayed for the presence of EH (Fig. 2B), only the lateral regions were found to have substantial amounts of bioactive material. The medial regions possessed low levels of EH activity, and the ventral regions none at all. These results strongly indicated that at least some of the protocerebral neurosecretory cells (but not the tritocerebral clusters) produce biologically active EH. Since numcrous studies have found significant amounts of neurosecretory material in the dendrites and central processes of insect peptidergic cells (Agricola et al., 1985; Geldiay and Edwards, 1973; Pipa, 1978; Veenstra et al., 1985), we chose the more rigorous approach of single-cell dissections to identify the clusters that produce $\mathrm{EH}$.

As previously noted, the large protocerebral neurosecretory cells in the developing adult moth brain are clearly visible (Fig. $3 A$ ). Following enzymatic treatment, the individual somata of the various groups were removed from the surrounding tissue and freed from contaminating material (Fig. $3 B$ ). The isolated somata from both sides of the brain were then pooled by group and bioassayed. As shown in Figure 4, the cells of the ipsilateral clusters (Group Ia) contained significant amounts of $\mathrm{EH}$, while no detectable levels of the hormone were found in either the contramedial (Groups IIa and IIb) or contralateral (Group III) clusters. The combined results of these experiments are summarized in Table 1.

In an attempt to localize $\mathrm{EH}$ within a subset of the ipsilateral neurosecretory clusters, the Group Ia cells were next subdivided 


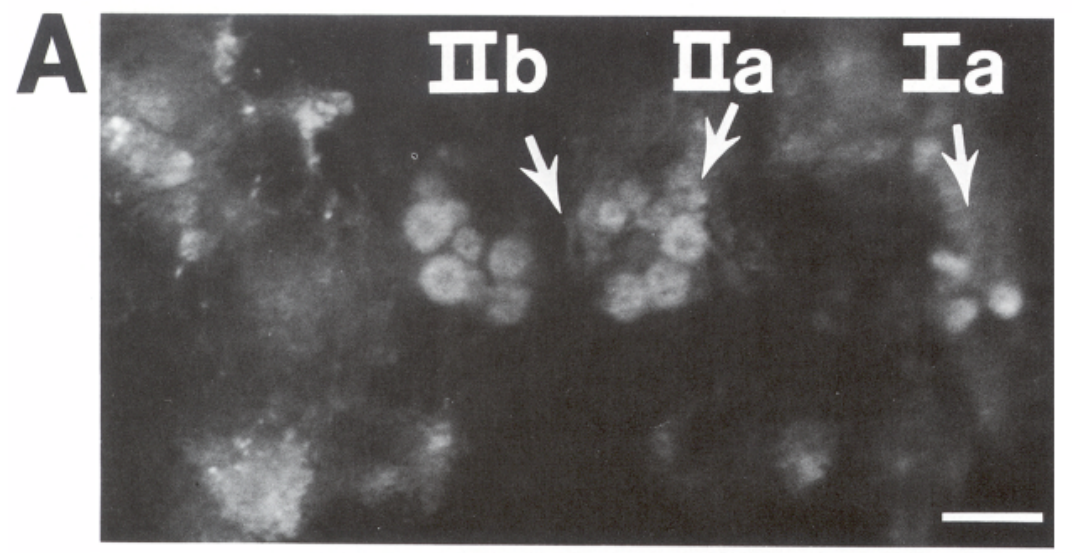

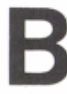

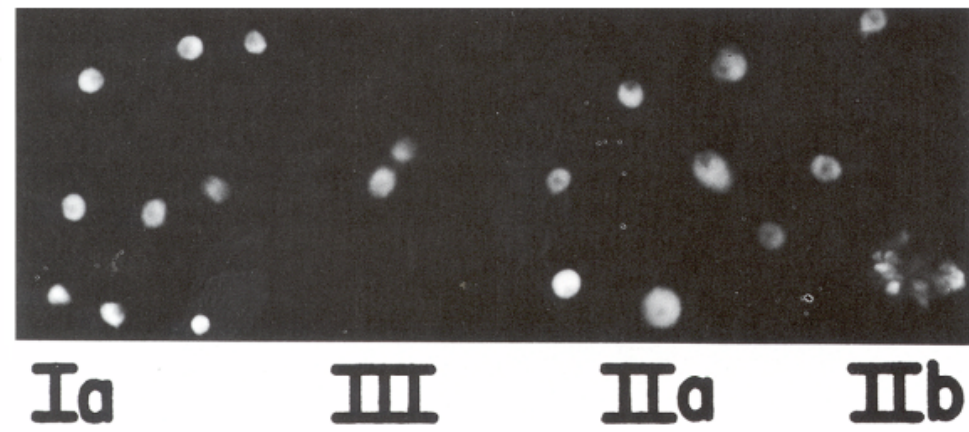

Figure 3. A, Photomicrograph of the protocerebral neurosecretory cells (dorsal view) in an unstained, desheathed brain dissected from a developing adult moth. Not all of the lateral cells (Groups Ia and III) are visible in this perspective. $B$, Protocerebral neurosecretory cells from one side of an adult moth brain following enzymatic treatment and dissection. The small Group IIb cells have been kept in a tight cluster. Scale, $100 \mu \mathrm{m}$. on the basis of soma position. Bioassays performed on subgroups of these cells yielded equivocal results, however, with no clear indication of the actual number of cells that produce $\mathrm{EH}$ (not shown). There was significant variability in the relative positions of the Group Ia cell bodies, and the similarity in size and color of their somata did not permit individual cells to be distinguished. Nevertheless, these results strongly indicated that at least some of the Group Ia cells are responsible for the production of EH in the brain of developing adult Manduca.

\section{Intracellular stimulation of $\mathrm{EH}$ release}

The electrophysiological and anatomical characteristics of the Group Ia neurosecretory cells were examined in semi-intact preparations by penetrating individual somata with micropipette elecrodes. Typical resting potentials of the ipsilateral cells were -35 to $-50 \mathrm{mV}$. Stimulation of individual cells with depolarizing pulses of current (Fig. 5A) produced a low-frequency burst of action potentials $(1-2 \mathrm{~Hz}, 35-50 \mathrm{mV})$ of long duration (20-45 msec), which in some preparations were seen to overshoot. Impulses recorded from spontaneously active cells exhibited similar waveform characteristics and also displayed an after-hyperpolarization phase lasting up to $200 \mathrm{msec}$ (Fig. $5 B)$.

Intracellular iontophoresis of cobalt chloride into individual ipsilateral cells revealed a distinctive morphology (Fig. 5C). A single neurite extended from each soma and gave rise to several large collaterals, which in turn produced a diffuse dendritic arbor extending across the superficial regions of the ipsilateral protocerebrum; this arbor typically included a few processes that crossed the dorsal midline of the brain. The major neurite itself continued ventrally as the axon through the ipsilateral NCC$1+2$, branching within the neurohemal organs to give rise to a diffuse terminal arbor. In all preparations where a Group Ia cell appeared to be filled completely, this terminal arbor ramified through the superficial regions of both the CC and CA, suggesting that the cells of this cluster secrete their contents directly into the hemolymph surrounding the retrocerebral complex.
Neurosecretory cells of the 3 major groups in the dorsal protocerebrum were individually stimulated by intracellular injection of depolarizing pulses of current. As shown in Figure 6, when a cell in Group Ia was briefly stimulated (10 min at $1-2$ $\mathrm{Hz}$ ) and a sample of the saline from around the CC-CA collected just before and after the period of excitation, EH activity was clearly detectable in the poststimulation bath. In contrast, intracellular stimulation of either Group IIa or Group III cells

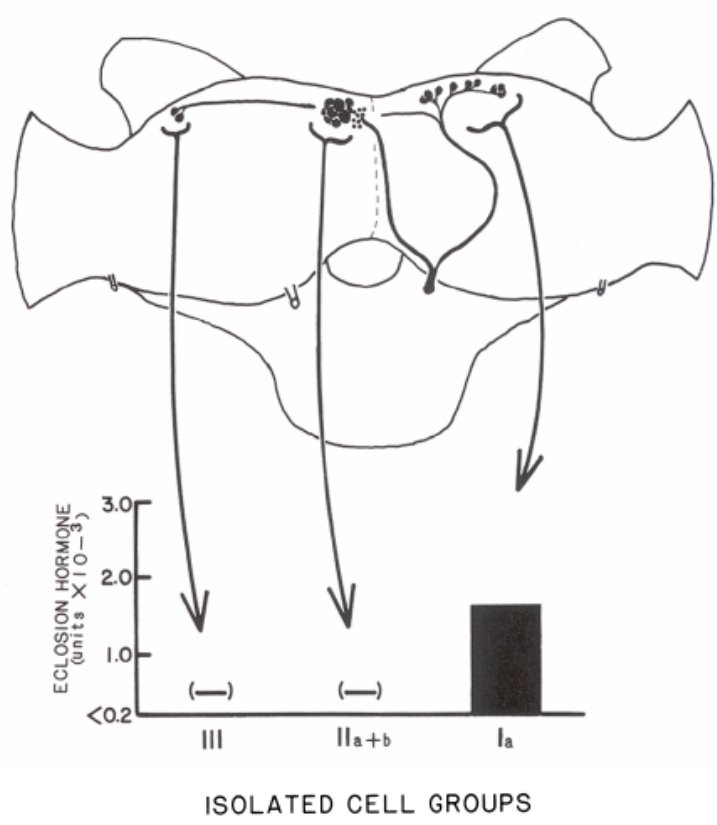

Figure 4. Bioassay of the isolated neurosecretory cells following dissection from a developing adult brain. The somata from both sides of the brain were pooled by group prior to cell lysis and then injected into an individual bioassay animal. (Summed results are in Table 1.) 

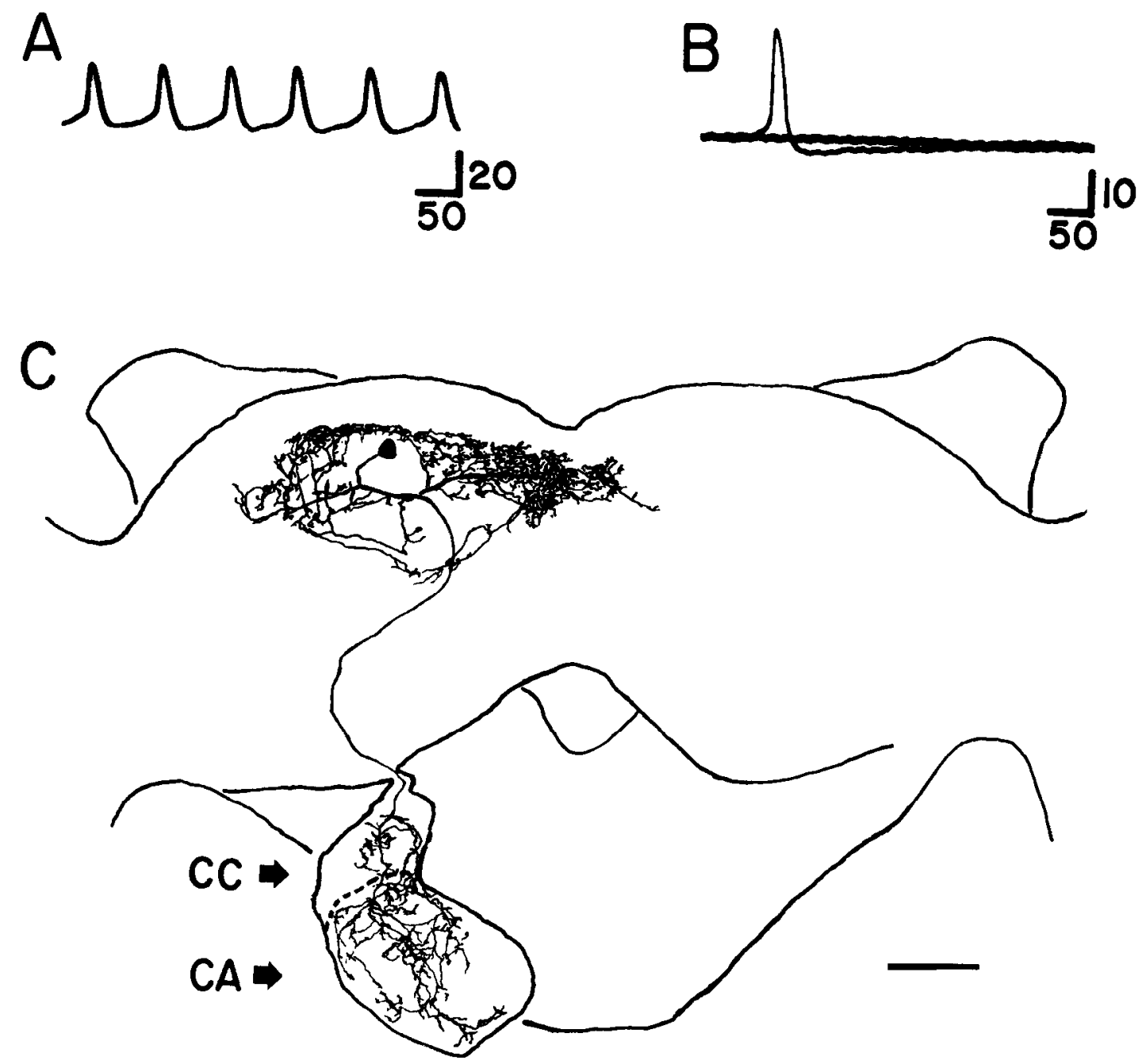

Figure 5. A, Repetitive firing of a Group la neurosecretory cell in response to an intracellular injection of depolarizing current (5 nA). B, Spontaneous action potential from a Group Ia cell. Horizontal scale, in msec; vertical scale, in $\mathrm{mV}$. $C$, Camera lucida drawing of a Group Ia cell (posterior view) following intracellular iontophoresis of cobalt. The central processes are largely confined to the superficial regions of the protocerebrum, while the terminal branches extend into both the $\mathrm{CC}$ and CA. Scale, $0.1 \mathrm{~mm}$.

caused no release of EH. As with the cell-dissection experiments described above (Fig. 4), the bioassay results of Figure 6 are based on small sample sizes due to the minute volumes of saline collected from around the neurohemal organs, but detectable levels of EH were recovered following stimulation of Group Ia cells in $44 \%$ of the preparations attempted (Table 2). Once again, the variability in soma position within the ipsilateral clusters precluded an assessment of the exact number of cells that contain the hormone; notwithstanding, these results support the conclusion that some (if not all) of the Group Ia cells produce and release $\mathrm{EH}$.

\section{Table 1. Eclosion hormone content in the dissociated somata of the} cerebral neurosecretory cell groups

\begin{tabular}{lll} 
Cell group & $\begin{array}{l}\text { Bioassay score } \\
( \pm \mathrm{SE})^{b}\end{array}$ & Equivalent EH units \\
\hline Ia & $76 \pm 4.6$ & $1.2 \pm 0.6 \times 10^{-3}$ \\
IIa $+\mathrm{b}$ & $46 \pm 1.3$ & $<0.2 \times 10^{-3}$ \\
III & $47 \pm 1.5$ & $<0.2 \times 10^{-3}$
\end{tabular}

a Each assay animal received the pooled cells from both sides of a single adult moth brain.

"Data summed for 11 trials.

\section{Immunological detection of $E H$}

Having identified the cells that produce EH on the basis of biological activity, we next attempted to confirm these results by immunohistochemical analysis. The production of a polyclonal antibody to the peptide was accomplished by immunizing a rabbit to conjugated fractions of EH. By monitoring the serum with an immunoprecipitation reaction, we first detected the presence of EH-binding activity following the third boost (approximately 7 weeks after the initial injection) and recovered maximal levels of activity at about 20 weeks. As shown in Figure 7 , the experimental serum (diluted 1:10) exhibited a strong affinity for $\mathrm{EH}$, removing all detectable bioactive material from an extract containing the hormone. The preimmune serum failed to reduce the levels of $\mathrm{EH}$ in an identical sample.

To examine the specificity of the antibody, aliquots of the immune serum were preincubated with extracts prepared from a variety of tissues prior to the immunoprecipitation reaction (Fig. 7). Homogenates of larval muscle and fat body were ineffective in preventing the serum's ability to precipitate $\mathrm{EH}$, while extracts derived from optic lobes (a region of the CNS devoid of biologically active EH) caused only a small decrement in the potency of the serum. In contrast, preincubation with an extract of the protocerebral lobes (containing the neurosecretory cell 

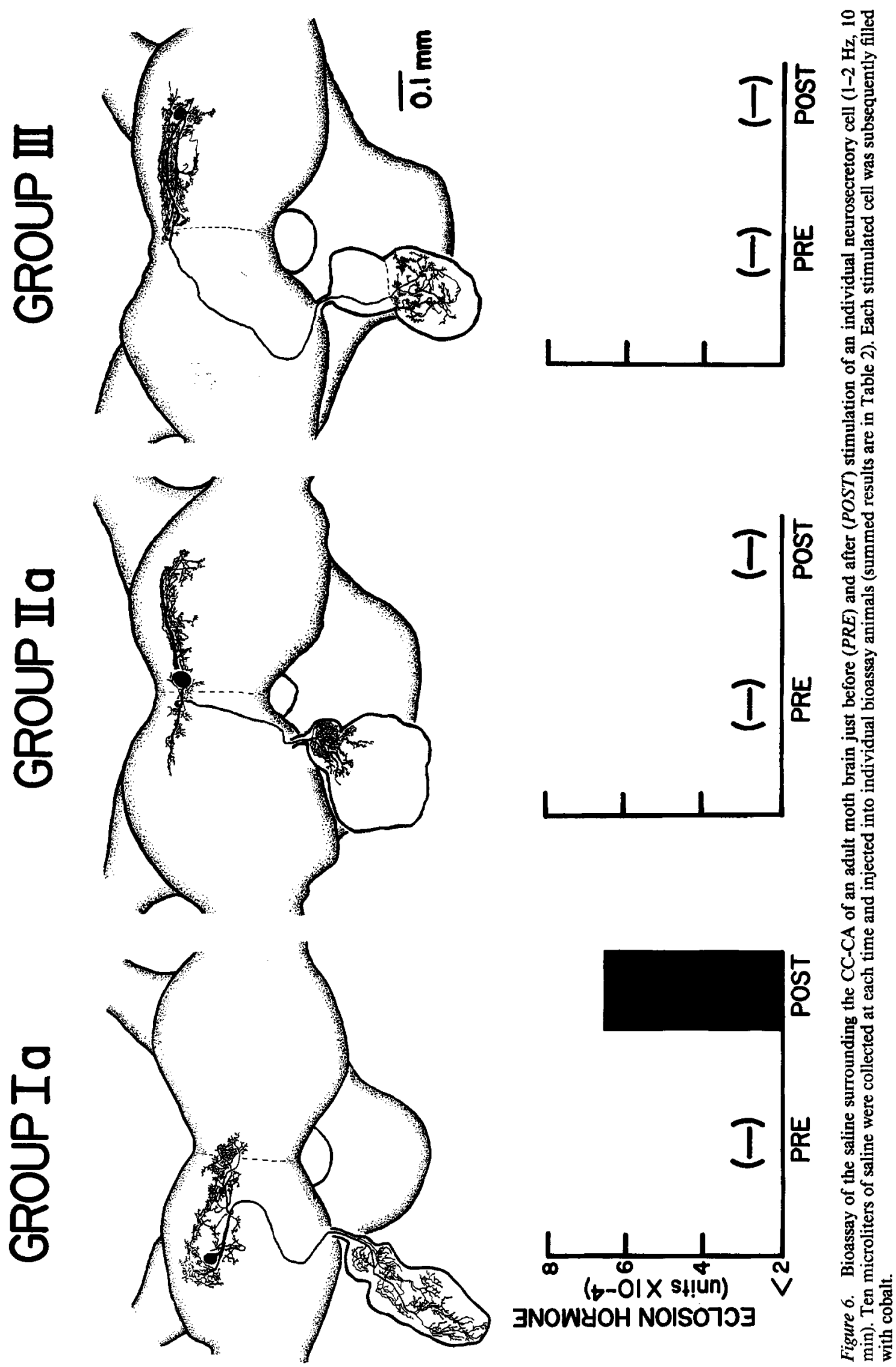


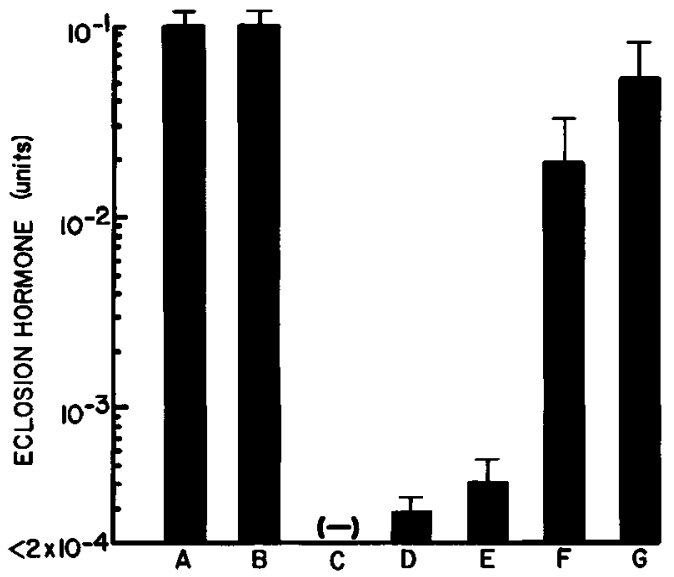

Figure 7. Biological activity ( \pm SE) in identical extracts of $\mathrm{EH}$ ( 3 units in $100 \mu \mathrm{l}$ ) following immunoprecipitation. $A$. Bioassay of a nonprecipitated extract of EH. $B$, Immunoprecipitation with preimmune serum. $C$. Immunoprecipitation with anti-EH antiserum. $D-G$, Immunoprecipitation with anti-EH antiserum following preincubation of the serum with homogenates from a variety of tissues: larval muscle and fat body $(D)$, adult moth optic lobes $(E)$, adult moth protocerebral lobes $(F)$, extracts of EH prepared from adult moth CC-CA $(G) .(n=10$ for each histogram.)

clusters), or with a sample of EH prepared from the CC-CA, resulted in a significant reduction of the antibody's binding activity, as indicated by the retention of bioactive material in the supernatant following immunoprecipitation. These experiments demonstrated a direct correlation between the presence of EH in a particular tissue extract and its effectiveness in blocking the serum's ability to bind EH.

The antibody was next used immunohistochemically to stain serial sections of paraffin-embedded adult brains by the indirect immunofluorescent technique (Sternberger, 1979). Exposure of the tissue sections first to the anti-EH antiserum and then to goat anti-rabbit IgG conjugated to fluorescein isothiocyanate revealed 5 large cell bodies in the lateral region of both protocerebral lobes (Fig. 8), clearly identifiable as members of the Group Ia cells by their size and position (Copenhaver and Truman, 1986a). Immunoreactive material could also be traced into the major neurites of these cells in the lateral protocerebrum (Fig. 8C) and was found in a network of beaded terminals in both the CC and CA (Fig. 8D), similar in appearance to neurohemal endings described in other systems (Beltz and Kravitz, 1983; Raabe, 1983; Schwarz et al., 1984). Thus, the distribution of immunoreactive EH directly coincided with the central and peripheral projection patterns of the Group Ia cells. In contrast, the Group IIa and Group III cells did not react positively to the antiscrum (Fig. $8 A, B$ ), nor did any other neurons in the brain. Preincubation of the immune serum with HPLC-purified EH (500 units added to $100 \mu l$ of serum) dramatically reduced the staining of both the cells and their processes (Fig. 8E, $F$ ), indicating that the antibody binds specifically to antigens related to EH. These results corroborated the localization of the EH neurons (made on the basis of biological activity) to the Group Ia clusters, but indicated that only a subset of these cells contains the peptide.

\section{Discussion}

We have identified a discrete set of neurosecretory cells in the developing adult moth brain (the Group Ia cells) that contains $\mathrm{EH}$, both by microdissection and bioassay of the neurosecretory somata and by electrical stimulation of individual cells within this group to induce hormone release. In addition, we have developed a serum antibody for $\mathrm{EH}$ that selectively stains 5 of the 9 Group Ia cells on either side of the brain, as well as their major neurites and terminal processes in the associated neurohemal organs. Although variability in the relative positions of the Group Ia somata precludes the unambiguous identification of unique individuals within this cluster, the similarities in their morphology, electrophysiological properties, and immunoreactivity indicate that the $\mathrm{EH}$-producing cells may represent a functionally homogeneous group.

Previous studies have shown that most of the cerebral neurosecretory cells of Manduca project to particular regions of the CC-CA-aortal complex (Carrow et al., 1984; Copenhaver and Truman, 1986a), reflecting the localized release sites of many of the hormones associated with the insect brain (e.g., Agui et al., 1980; Mordue, 1970; Nicolson, 1976; Spring and Phillips, 1980). EH bioactivity has been found to be stored and secreted from both the $\mathrm{CC}$ and $\mathrm{CA}$ in approximately equal quantities (Copenhaver and Truman, 1986b), and all of the Group Ia cells examined by cobalt iontophoresis in this study projected to both of these regions. Immunoreactive material revealed by the antiserum to EH was similarly distributed. While the functional significance of this diffuse pattern of neurohemal arborization remains unknown, the correlation between the distribution of EH bioactivity, immunoreactivity, and the terminal processes of the Group Ia cluster provides additional evidence that this group contains the EH-producing neurons of the brain.

The electrophysiological characteristics of the ipsilateral cells were similar to those reported for neurosecretory cells in the pupal stage of Manduca (Carrow et al., 1984) and in other insects (Cook and Milligan, 1972; Orchard, 1983; Wilkens and Mote, 1970; Zaretsky and Loher, 1983): They produced large, overshooting action potentials of relatively long duration followed by a prolonged after-hyperpolarization, and responded to a sustaincd pulse of depolarizing current with a low-frequency burst of action potentials. Somatic potentials in neurosecretory cells of other lepidopteran preparations have been shown to be dependent on external calcium and (to a lesser degree) on sodium (Carrow et al., 1984; Miyazaki, 1980; Yagi and Iwasaki, 1977); presumably the EH-producing cclls of adult Manduca rely on similar ionic conductance mechanisms.

Electrical stimulation of individual Group Ia somata induced

Table 2. Induction of eclosion hormone release from the $\mathrm{CC}-\mathrm{CA}$ in response to intracellular stimulation of cells within the various cerebral neurosecretory cell groups

\begin{tabular}{lllc} 
Cell group & $\begin{array}{l}\text { No. } \\
\text { stimulated }\end{array}$ & $\begin{array}{l}\text { No. } \\
\text { released EH }\end{array}$ & Latencies of response $(\mathrm{min})$ \\
\hline Ia & 18 & 8 & $75,135,145,149,149,164,175,175,178,185$, \\
& & & $188,188,200,200,208,213,250,250$ \\
IIa & 5 & 0 & $196,200,204,204,213$ \\
III & 5 & 0 & $188,196,204,222,233$
\end{tabular}

${ }^{a}$ Latencies less than 176 min (equivalent to bioassay scores greater than 56 , or $2 \times 10^{-4}$ units of EH) were considered positive. 

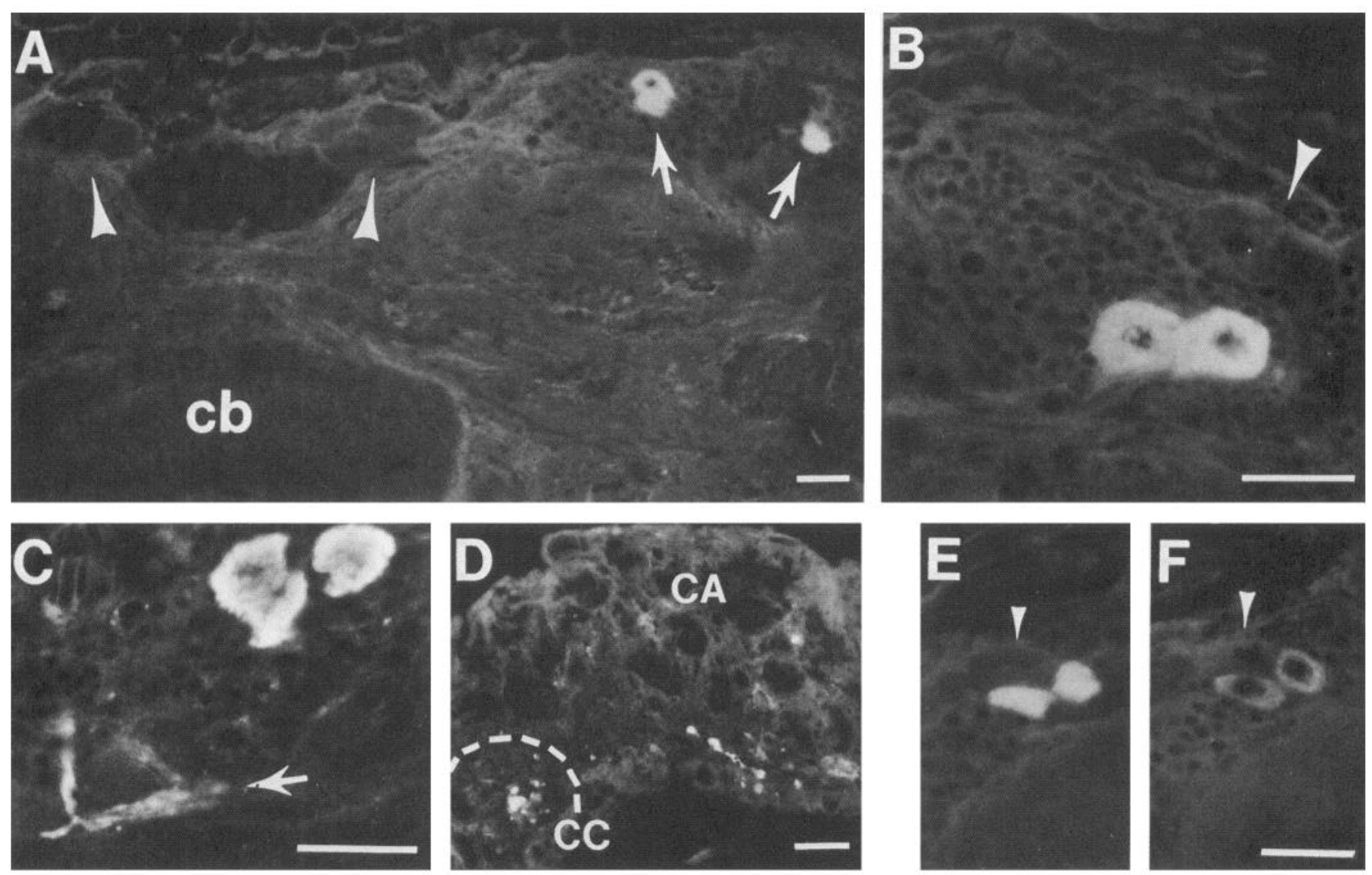

Figure 8. Fluorescent staining of sectioned adult brains following incubation with the anti-EH antiserum. A, Frontal section showing 3 of the Group Ia cells in the right protocerebrum stained positively (arrows); several Group II cells on either side of the midline (arrowheads) showed no reaction. $(C B=$ central body). $B$, Enlarged view of a similar section, showing 2 stained Group Ia cells adjacent to the unstained Group III cells (arrowhead). C, Positive reactivity within the major neurites (arrow) of several of the Group Ia cells in the lateral protocerebrum. $D$, Immunoreactive material within beaded varicosities in both the $C C$ and $C A$ of the neurohemal complex. $E$ and $F$, Adjacent sections of an adult brain treated alternately with anti-EH antiserum $(E)$ or with serum preincubated with HPLC-purified EH $(F)$. Two of the Group Ia cells in these sections reacted positively to the serum, while a third (arrowhead) did not. Scale, $25 \mu \mathrm{m}$.

the secretion of $\mathrm{EH}$ in $44 \%$ of the preparations (Table 2). This result is consistent with the observation that only a subset of the ipsilateral cells contained immunoreactive EH. Intracellular stimulation of either the Group IIa or III cells failed to induce the release of EH bioactivity, illustrating that the secretion of the peptide following stimulation of the Group Ia cells was not simply due to nonspecific excitation of the cerebral neurosecretory system. In addition, extracellular monitoring of the neurosecretory nerves during intracellular stimulation of Group Ia cells has shown a one-for-one correspondence of impulses recorded from the soma and from their terminal regions in the CC-CA (Copenhaver and Truman, 1986b), while the terminal projections of the Group Ia cells into the more peripheral regions of the $\mathrm{CC}$ and CA provide a morphological basis for the direct secretion of their contents into the surrounding hemolymph. Thus, the release of $\mathrm{EH}$ following excitation of the Group Ia cells was probably not due to synaptic activation of other secretory cells in either the brain or the CC-CA.

The polyclonal antiserum prepared against $\mathrm{EH}$ precipitated all biological activity from fractions containing the peptide and selectively stained a subset of the Group Ia cell bodies and their processes. Both of these reactions were markedly inhibited by preincubation of the antiserum with relatively small quantities of EH but were unaffected by preincubation with extracts that did not contain EH bioactivity. For immunohistochemical staining of sectioned brains, a relatively long incubation time with the primary antibody $(36-48 \mathrm{hr})$ was necessary to achieve optimal results. We also performed immunohistochemical staining on intact nervous tissue (not shown), using the wholemount procedure of Bishop and O'Shea (1982). Although those experiments revealed a staining pattern similar to that seen in sectioned material, the excessive levels of background reactivity that accompanied both experimental and control sera precluded the use of this technique for the accurate examination of immunoreactive structures.

A large number of hormonal factors in addition to $\mathrm{EH}$ have been attributed to the cerebral neurosecretory systems of insects (reviewed in Downer and Laufer, 1983; Raabe, 1982), but in only one previous instance-the localization of prothoracicotropic hormone to the Group III cell clusters of pupal Manduca (Agui et al., 1979) - has the function of an identified set of brain neurosecretory cells been unambiguously confirmed. Similarly, the physiological changes accompanying the release of many of these factors have been examined, primarily with extracellular recording (Copenhaver and Truman, 1984; Orchard and Steel, 1980; Ruegg et al., 1982) and stimulating techniques (Girardie and Girardie, 1977; Orchard et al., 1981; Scharrer and Kater, 1969). However, an accurate determination of the mechanisms whereby both internal and environmental factors impinge on neurosecretory events requires a more rigorous intracellular analysis using identified neurons. The localization of the cerebral neurosecretory cells that produce $\mathrm{EH}$ will now permit a direct examination of the effects of a variety of physiologically relevant stimuli on the release of this peptide hormone. 


\section{References}

Agricola, H., M. Eckert, J. Ude, H. Birkenbeil, and H. Penzlin (1985) The distribution of a proctolin-like immunoreactive material in the terminal ganglion of the cockroach, Periplaneta americana L. Cell Tissue Res. 239: 203-209.

Agui, N., N. A. Granger, L. I. Gilbert, and W. E. Bollenbacher (1979) Cellular localization of the insect prothoracicotropic hormone: In vitro assay of a single neurosecretory cell. Proc. Natl. Acad. Sci. USA 76: 5694-5698.

Agui, N., W. E. Bollenbacher, N. A. Granger, and L. I. Gilbert (1980) Corpus allatum is the release site for insect prothoracicotropic hormone. Nature 285: 669-670.

Bacon, J. D., and J. S. Altman (1977) A silver intensification method for cobalt-filled neurons in whole mount preparations. Brain Res. 138: 359-363.

Bell, R. A., and F. G. Joachim (1976) Techniques for rearing laboratory colonies of tobacco hornworms and pink bollworms. Ann. Entomol. Soc. Am. 69: 365-373.

Beltz, B. S., and E. A. Kravitz (1983) Mapping of serotonin-like immunoreactivity in the lobster nervous system. J. Neurosci. 3: 585602.

Berlind, A., and S. H. P. Maddrell (1979) Changes in hormone activity of single neurosecretory cell bodies during a physiological secretion cycle. Brain Res. 161: 459-467.

Bishop, C. A., and M. O'Shea (1982) Neuropeptide proctolin (H-argtyr-leu-pro-thr-OH): Immunocytochemical mapping of neurons in the CNS of the cockroach. J. Comp. Neurol. 207: 223-238.

Bruce, I. C., and J. L. Wilkens (1976) Neuronal activity in neurosecretory cells of the fieshfly, Sarcophaga bullata. J. Comp. Physiol. 112: 109-122.

Bulinski, J. C., S. Kumar, K. Titani, and S. D. Hauschka (1983) Peptide antibody specific for the amino terminus of skeletal muscle a-actin. Proc. Natl. Acad. Sci. USA 80: 1506-1510.

Bullock, T. H. (1984) Comparative neuroscience holds promise for quiet revolution. Science 225: 473-478.

Buys, C. M., and D. Gibbs (1981) The anatomy of neurons projecting to the corpus cardiacum from the larval brain of the tobacco horrworm, Manduca sexta (L). Cell Tissue Res. 215: 505-513.

Carrow, G. M., R. L. Calabrese, and C. M. Williams (1984) Architecture and physiology of insect cerebral neurosecretory cells. J. Neurosci. 4: 1034-1044.

Chedid, L., F. Audibert, P. Lefrancier, J. Choay, and E. Lederer (1976) Modulation of the immune response by a synthetic adjuvant and analogs. Proc. Natl. Acad. Sci. USA 73: 2472-2475.

Cook, D. J., and J. V. Milligan (1972) Electrophysiology and histology of the medial neurosecretory cells in adult male cockroaches, Periplaneta americana. J. Insect Physiol. 18: 1197-1214.

Copenhaver, P. F., and J. W. Truman (1982) The role of eclosion hormone in the larval ecdyses of Manduca sexta. J. Insect Physiol. 28: 695-701.

Copenhaver, P. F., and J. W. Truman (1984) Spontaneous and induced release of the peptide eclosion hormone from identified neurons in the moth Manduca sexta. Soc. Neurosci. Abstr. 10: 153.

Copenhaver, P. F., and J. W. Truman (1986a) Metamorphosis of the cerebral neurosecretory system in the moth Manduca sexta. J. Comp. Neurol. (in press).

Copenhaver, P. F., and J. W. Truman (1986b) Control of neurosecretion in the moth Manduca sexta: Physiological regulation of the eclosion hormone cells. J. Comp. Physiol. (in press).

Downer, R. G. H., and H. Laufer, eds. (1983) Endocrinology of the Insects. Alan Liss, New York.

Geldiay, S., and J. S. Edwards (1973) The protocerebral neurosecretory system and associated cerebral neurohemal area of Acheta domesticus. Z. Zellforsch. 145: 1-22.

Giloh, H., and J. W. Sedat (1982) Fluorescence microscopy: Reduced photobleaching of rhodamine and fluorescein protein conjugates by n-propyl gallate. Science 217: 1252-1255.

Girardie, J., and A. Girardie (1977) Liberation provoquee in vitro du produit de neurosecretion des cellules protocerebrales medianes chez le criquet migrateux. J. Physiol. (Paris) 73: 707-721.

Jones, P. P. (1980) Analysis of radiolabelled lymphocyte proteins by one- and two-dimensional polyacrylamide gel electrophoresis. In $\mathrm{Se}$ lected Methods of Cellular Immunology, B. B. Mishell and S. M. Shiigi, eds., pp. 368-440, Freeman, San Fransisco.

Miyazaki, S.-I. (1980) The ionic mechanism of action potentials in neurosecretory cells and non-neurosecretory cells of the silkworm. J. Comp. Physiol. 140: 43-52.

Mordue, W. (1970) Evidence for the existence of diuretic and antidiuretic hormones in locusts. J. Endocrinol. 46: 119-120.

Nicholson, $S$. (1976) The hormonal control of diuresis in the cabbage white butterfly Pieris brassicae. J. Exp. Biol. 65: 565-576.

Nicholson, S., J.-H. Lin, S. Mahmoud, E. Cambell, B. Gilham, and M. Jones (1985) Diurnal variations in responsiveness of the hypothalamo-pituitary-adrenocortical axis of the rat. Neuroendocrinology 40 217-224.

Nijhout, H. F. (1975) Axonal pathways in the brain-retrocerebral neuroendocrine complex of Manduca sexta. Int. J. Insect Morphol. Embryol. 4: 529-538.

Orchard, I. (1983) Neurosecretion: Morphology and physiology. In Endocrinology of Insects, R. G. H. Gainer and H. Laufer, eds., pp. 13-38, Alan Liss, New York.

Orchard, I., and C. G. H. Steel (1980) Electrical activity of neurosecretory axons from the brain of Rhodnius prolixus: Relation of changes in the patterns of activity to endocrine events during the moulting cycle. Brain Res. 191: 53-65.

Orchard, I., T. Friedel, and B. G. Loughton (1981) Release of neurosecretory protein from the corpora cardiaca of Locusta migratoria induced by high potassium saline and compound action potentials. J. Insect Physiol. 27: 297-304.

O'Shea, M., and M. E. Adams (1981) Pentapeptide (proctolin) associated with an identified neuron. Science 213: 567-569.

O'Shea, M., and C. A. Bishop (1982) Neuropeptide proctolin associated with an identified skeletal motoneuron. J. Neurosci. 2: 12421251 .

Pipa, R. L. (1978) Locations and central projections of neurons associated with the retrocerebral neuroendocrine complex of the cockroach Periplaneta americana (L). Cell Tissue Res. 193: 443-455.

Raabe, M. (1982) Insect Neurohormones, Plenum, New York.

Raabe, M. (1983) The neurosecretory-neurohemal system of insects; anatomical, structural, and physiological data. Adv. Insect Physiol. 17: 205-303.

Reynolds, S. E., and J. W. Truman (1980) Eclosion hormones. In Neurohormonal Techniques in Insects, T. A. Miller, ed., pp. 196-215, Springer-Verlag, New York.

Rowell, H. F. (1976) The cells of the insect neurosecretory system: Constancy, variability and the concept of the unique identifiable neuron. Adv. Insect Physiol. 12: 63-123.

Ruegg, R. P., I. Orchard, and K. G. Davey (1982) 20-Hydroxyecdysone as a modulator of electrical activity in neurosecretory cells of Rhodnius prolixus. J. Insect Physiol. 28: 243-248.

Scharrer, B., and S. B. Kater (1969) Neurosecretion. XV. An electronmicroscopic study of the corpora cardiaca of Periplaneta americana after experimentally induced hormone release. Z. Zellforsch. Mikrosk. Anat. 95: 177-186.

Schwartz, L. M., and J. W. Truman (1983) Hormonal control of rates of metamorphic development in the tobacco hornworm Manduca sexta. Dev. Biol. 99: 103-114.

Schwartz, L. M., and J. W. Truman (1984) Cyclic GMP may serve as a second messenger in peptide-induced muscle degeneration in an insect. Proc. Natl. Acad. Sci. USA 81: 6718-6722.

Schwarz, T. L., G. M.-H. Lee, K. Siwicki, D. G. Standaert, and E. A. Kravitz (1984) Proctolin in the lobster: The distribution, release, and chemical characterization of a likely neurohormone. J. Neurosci. 4: $1300-1311$.

Spring, J. H., and J. E. Phillips (1980) Studies on locust rectum. II. Identification of specific ion transport processes regulated by corpora cardiaca and cyclic AMP. J. Exp. Biol. 86: 225-236.

Sternberger, L. A. (1979) Immunocytochemistry, Wiley, New York.

Taghert, P. H., and J. W. Truman (1982) Identification of the bursiconcontaining neurons in abdominal ganglia of the tobacco hornworm, Manduca sexta. J. Exp. Biol. 98: 385-401.

Truman, J. W. (1971) Physiology of insect ecdysis. I. The eclosion behavior of saturniid moths and its hormonal release. J. Exp. Biol. 54: 805-814.

Truman, J. W. (1972) Physiology of insect rhythms. II. The silkmoth brain as the location of the biological clock controlling eclosion. $J$. Comp. Physiol. 81: 99-114.

Truman, J. W. (1980) Eclosion hormone: Its role in coordinating ecdysteroid events in insects. In Insect Biology in the Future, M. Locke and D. S. Smith, eds., pp. 385-401, Academic, New York.

Truman, J. W., P. H. Taghert, P. F. Copenhaver, N. J. Tublitz, and L. 
M. Schwartz (1981) Eclosion hormone may control all ecdyses in insects. Nature 291: 70-71.

Truman, J. W., D. B. Roundtree, S. E. Reiss, and L. M. Schwartz (1983) Ecdysteroids regulate the release and action of eclosion hormone in the tobacco hornworm, Manduca sexta. J. Insect Physiol. 29: 895900.

Tublitz, N. J., and J. W. Truman (1985) Insect cardioactive peptides: I. Distribution and molecular characterization of two cardioacceleratory peptides (CAPs) in the tobacco hawkmoth, Manduca sexta. J. Exp. Biol. 114: 365-380.

Veenstra, J. A., H. M. Romberg-Privee, H. Schooneveld, and J. M. Polak (1985) Immunocytochemical localization of peptidergic neurons and neurosecretory cells in the neuro-endocrine system of the
Colorado potato beetle with antisera to vertebrate regulatory peptides. Histochemistry 82: 9-18.

Watson, S. J., and H. Akil (1983) Immunocytochemistry of peptides In Current Methods of Cellular Neurobiology, Vol. 1, J. L. Barker and J. F. McKelvy, eds., pp. 111-132, Wiley, New York.

Wilkens, J. L., and M. I. Mote (1970) Neuronal properties of the neurosecretory cells in the fly Sarcophaga bullata. Experientia 26: 275-276.

Yagi, K., and S. Iwasaki (1977) Electrophysiology of the neurosecretory cell. Int. Rev. Cytol. 48: 141-186.

Zaretsky, M., and W. Loher (1983) Anatomy and electrophysiology of individual neurosecretory cells of an insect brain. J. Comp. Neurol. 216: 253-263. 